\title{
Usage patterns of transdermal nicotine when purchased as a non-prescription medicine from pharmacies
}

\author{
John P Shaw, Donald G Ferry, Damian Pethica, Daniel Brenner, Ian G Tucker
}

\begin{abstract}
Objective-To assess nicotine patch use in smokers who purchased the product as a non-prescription medicine from pharmacies.

Design-A questionnaire administered at the time of purchase.

Setting-Community pharmacies throughout New Zealand.

Subjects-A total of 805 male and female purchasers of nicotine patches aged 18 through 87 years.

Main outcome measures-Patterns of usage including self-reported smoking history, previous quit-smoking attempts, previous and current use of transdermal nicotine and other products, side effects, and concomitant smoking.

Results-Most respondents (74\%) had attempted to quit smoking previously, many of whom (53\%) had used a non-prescription nicotine replacement product. Approximately $60 \%$ of purchasers were first-time users. For those continuing a course of treatment, there was no evidence of use for longer than the manufacturer's recommendation (12 weeks). Twenty-eight per cent of respondents reported continuing smoking while using transdermal nicotine, although the number of cigarettes smoked was much less than in the reported smoking history. Side effects were reported by $24 \%$ of patch users in the current course, but there was no evidence of significant safety problems. Conclusions-This survey provides preliminary data on the non-prescription usage of transdermal nicotine when purchased through pharmacies.

(Tobacco Control 1998;7:161-167)
\end{abstract}

Keywords: nicotine replacement therapy, nicotine skin patch, transdermal nicotine, over-the-counter medication

\section{Introduction}

The nicotine patch is a transdermal delivery system which is used as an aid to overcome nicotine dependence during attempts to stop smoking. It is supplied as a course of treatment with the intent of "weaning" the user off nicotine dependence by gradually reducing the amount/dose of nicotine delivered through the skin. ${ }^{1-4}$ The length of treatment recommended by various manufacturers varies between eight and 18 weeks, and the total weeks of treatment in controlled clinical trials has ranged from two to 18 weeks. $^{56}$ Other nicotine replacement products include nicotine gum, which has been widely used since the early 1980s, and the recently introduced nicotine nasal sprays and inhalers. ${ }^{7-10}$

The nicotine patch has been available worldwide since about the early 1990s. In the United States it was released as a prescription medicine in $1991 .^{11}$ In some countries, it has been available as a non-prescription medicine for several years and recently the Food and Drug Administration approved over-the-counter (OTC) use of this product in the United States. ${ }^{12}$ In New Zealand, the product Nicotinell TTS (known as Habitrol in the United States) was launched as a pharmacyonly medicine (OTC sale only in a registered pharmacy) in 1990, this being the first country to allow non-prescription sale. ${ }^{13}$ There are three patch sizes: Nicotinell TTS $10\left(10 \mathrm{~cm}^{2}\right)$, $20\left(20 \mathrm{~cm}^{2}\right)$, and $30\left(30 \mathrm{~cm}^{2}\right)$, delivering $7 \mathrm{mg} /$ day, $14 \mathrm{mg} /$ day, and $21 \mathrm{mg} /$ day of nicotine, respectively. The usual pack size of the product is seven patches, with the maximum pack containing 21 patches. This presents the opportunity for pharmacists to provide repeated counselling and discussion with users. ${ }^{13} 14$

The effectiveness of the nicotine patch for smoking cessation has been evaluated in a variety of settings, and a meta-analysis of 17 double-blind, placebo-controlled studies reported overall abstinence rates for the active patch of $27 \%$ (vs $13 \%$ for placebo) at the end of treatment and $22 \%$ (vs $9 \%$ for placebo) at six months. ${ }^{6}$ The authors of the meta-analysis pointed out that there were still many unanswered questions in the use of the nicotine patch. These questions include, for example, the optimal duration of treatment, the choice of product and patch strength, the level of adjuvant counselling required, and the safety, tolerability, and dependence liability of the product in "real life" settings. Many of these questions cannot be answered using the traditional clinical trial study design.

In an attempt to assess the use of transdermal nicotine in "real-world" patch users, a survey of older (65-74 years), long-term, heavy smokers filling prescriptions for the product in Pennsylvania (United States) revealed an encouraging self-reported six-month quit rate $(29 \%)$, but a far from ideal compliance with patch use guidelines, little in the way of formal counselling, and a high level of concomitant smoking. ${ }^{15}$ Concomitant smoking was strongly associated with failure to achieve abstinence, and more frequent contact with physicians and pharmacists was associated with less concomitant smoking. This study emphasised the need 
for further research on the "real-world" use of transdermal nicotine, in particular, with non-prescription status.

Although some concerns have been raised that pharmacists may be ill-equipped for a role in smoking cessation, some authors have advocated a greater contribution because of the accessibility of pharmacy to the public. ${ }^{16-19} \mathrm{~A}$ study in Scotland demonstrated that smoking cessation rates for customers buying nicotine replacement therapy in community pharmacies seem to be comparable with those reported for other settings. ${ }^{20}$

One unknown in the non-prescription availability of nicotine products has been their dependence liability. Nicotine is the addictive component of tobacco, and rapidity of onset and frequency of use have been suggested as determinants of dependence potential. This being the case, nicotine sprays and aerosols should have dependence potential, but not nicotine patches. Surveys of transdermal nicotine usage and studies of subject effects are consistent with this notion. ${ }^{21-25}$ Physical dependence on nicotine gum has been reported in some users, and a substantial percentage of smokers who quit may persist in using the gum at one year. It must be noted, however, that this is not a clearcut issue. These studies involved the supervision of a physician, and the gum was obtained on prescription. In such instances its use may be quite appropriate in the context of relapse prevention, and it has been demonstrated that weaning even long-term users off nicotine gum is not difficult. ${ }^{26} 27$

One method to investigate the dependence potential of transdermal nicotine would be to document the duration of usage when the restriction of obtaining a physician's prescription is absent. We took this approach in our study to determine if any "transfer of addiction" from tobacco to the nicotine patch is occurring.

This article describes a survey involving purchasers of Nicotinell TTS without a prescription from community pharmacies in New Zealand. The objectives of the study were (a) to establish the present use and previous usage of this product by purchasers in relation to age, gender, smoking history, and previous quit-smoking attempts; (b) to record the level of self-reported concomitant smoking; (c) to document the incidence of self-reported side effects associated with the use of the product; (d) to determine if there was evidence of "transfer of addiction" associated with the use of transdermal nicotine.

\section{Methods}

STUDY POPULATION

The study was an open questionnaire survey involving purchasers of Nicotinell TTS from community pharmacies in New Zealand. These pharmacies are independently owned and operated, and approximately 1100 are distributed throughout the country, serving a population of 3.5 million. Pharmacies were identified using the Pharmacy Guild of New Zealand Directory of Retail Pharmacies, which gives a complete listing of pharmacies in New Zealand .
Before the study started, approval of the protocols and information sheet for volunteers was obtained from Ethics Committees throughout New Zealand. The study was conducted in accordance with Good Drug Monitoring Practice guidelines, and in compliance with the latest amendment of the Declaration of Helsinki. The study was administered from the country's single School of Pharmacy in Dunedin.

Two weeks before commencement of the study, letters were sent to all pharmacy managers of community pharmacies in New Zealand inviting them to participate in the study and outlining the rationale, objectives, and procedures. Copies of the questionnaire, consumer information sheet, pharmacist questionnaire guide, study protocol, and a customer record form were included. The letter advised pharmacists of the proposed period of sampling.

There was no active follow-up to this invitation; pharmacists elected to participate on a voluntary basis. Their role was to recruit purchasers of Nicotinell TTS into the study and to administer a short questionnaire on behalf of the researchers. The intention was to provide a "snapshot" of usage of Nicotinell TTS over a short timeframe. In this study, purchasers were surveyed only once, and this could be at any time during their treatment course with Nicotinell TTS.

\section{INTERVIEW}

The questionnaire guide for pharmacists included standard phrases to be used for inviting the consumers to participate. The questions to be asked of consumers were detailed in the questionnaire.

After purchase of Nicotinell TTS, purchasers were asked if they were the intended user of the product, and if so were they willing to participate in the study. The pharmacist then explained the nature of the study using the information sheet, which was given to consumers. This sheet outlined the aims of the study and emphasised the voluntary nature of participation and the anonymity of results. It also outlined the exclusion criteria-namely, consumers who had already participated in the study at any pharmacy, and purchasers who were buying the product on behalf of someone else. If the consumer gave verbal consent to participate, the pharmacist administered the questionnaire.

The pharmacist then asked the questions detailed on the questionnaire. These investigated age and smoking history; descriptions of the extent and duration of smoking and nature of the smoking product used; cessation history; descriptions of previous quit attempts; and product history, which detailed the use of Nicotinell TTS with regard to strength of patch used, duration of use, other products tried, and whether the consumer had continued to smoke during use of Nicotinell TTS. In addition, side effects from Nicotinell TTS use and pre-existing medical conditions were recorded. The questionnaire was specifically designed to be straightforward 
and quick to administer. It took about two or three minutes on average to complete the questionnaire.

DATA RECORDING AND ANALYSIS

On completion of the interview the pharmacist recorded the batch number of the Nicotinell TTS on the form and signed and dated the questionnaire. No record was kept regarding the number of purchasers who did not participate in the study.

The questionnaires were returned to the Investigating Center for data recording, and descriptive statistical analysis was performed using the Statistical Package for the Social Sciences (SPSS). To identify covariates of selected process and outcome measures, $\chi^{2}$ tests of independence were computed for categorical outcome variables, and $t$ tests for continuous variables.

The study was undertaken over a five-month period in 1993. A minimum of 800 responses was set as a reasonable target for the purposes of statistical analysis. At the time of commencement, Nicotinell TTS had been available for purchase through pharmacies in New Zealand for approximately 18 months.

\section{Results}

DEMOGRAPHIC AND SMOKING HISTORY DATA The total number of pharmacies generating participants was 149 of a total of 1108 contacted $(13.5 \%)$. The total number of questionnaires returned was 805 .

Table 1 presents demographic and smoking history characteristics of the participants. Men and women were almost equally represented. The average age of respondents was 41 years (median 39 years), ranging from 18 to 87 years. Sixteen years is the minimum age to purchase cigarettes in New Zealand. The average duration of smoking was 19.7 years (median 18 years), ranging from two months to 67 years. Cigarette consumption was the main method of smoking $(98 \%$ of respondents) with fewer than $2 \%$ reporting consumption of cigars or pipes as the main method. The average number of cigarettes smoked per day was 21.6 (median 20); the smallest number was two per day while one smoker consumed 75 per day.

PREVIOUS QUIT ATTEMPTS

Previous attempts to quit smoking had been made by 634 out of $805(78.8 \%)$ total respondents, with men and women almost equally represented. Of the 634 purchasers who had made previous attempts to quit smoking, 325 (51.3\%) reported the use of one

Table 1 Demographic and smoking history characteristics of 805 survey respondents

\begin{tabular}{llll}
\hline & $\begin{array}{l}\text { Total population } \\
\text { Mean (SD) }\end{array}$ & $\begin{array}{l}\text { Women } \\
\text { Mean (SD) }\end{array}$ & $\begin{array}{l}\text { Men } \\
\text { Mean }(S D)\end{array}$ \\
\hline Age (years) & $41.0(13.1)$ & $40.5(13.0)$ & $41.4(13.1)$ \\
& $\mathrm{n}=792 \dagger$ & $\mathrm{n}=394 \dagger$ & $\mathrm{n}=394 \dagger$ \\
Duration of smoking (years) & $19.7(12.5)$ & $19.0(11.9)$ & $20.4(13.1)$ \\
Cigarettes per day before patch & $\mathrm{n}=763 \dagger$ & $\mathrm{n}=378 \dagger$ & $\mathrm{n}=385 \dagger$ \\
& $21.6(8.9)$ & $19.8(8.3)$ & $23.4(9.3)$ \\
& $\mathrm{n}=778 \dagger$ & $\mathrm{n}=394 \dagger$ & $\mathrm{n}=384 \dagger$
\end{tabular}

†Number of respondents varies slightly because of partial completion of relevant questionnaire sections.
Table 2 Products used by 325 respondents in their previous quit attempts

\begin{tabular}{lll}
\hline & $\begin{array}{l}\text { Respondents who } \\
\text { had used products } \\
\text { previously } \\
(n=325)\end{array}$ & \\
Product used & $195(60)$ & $\begin{array}{l}\text { Total respondents } \\
(n=805) \%\end{array}$ \\
\hline Nicotinell TTS & $148(45.5)$ & 24.2 \\
Nicorette Gum & $8(2.5)$ & 18.4 \\
Nicabate TTS & $19(5.9)$ & 1.0 \\
Nicobrevin & $12(3.1)$ & 2.4 \\
Other & 1.5 \\
\hline
\end{tabular}

^Some respondents reported previous usage of more than one product.

or more nicotine-containing or other pharmaceutical products. This represents $40.4 \%$ of the total purchasers who completed the questionnaire. Analysis of the relationship between the use of nicotine-containing products, gender, and each of the number of years smoking, the number of cigarettes each day, and the age of the purchasers yielded no significant differences between the relevant subgroups.

Table 2 shows the products reported by the 325 respondents who had used one or more products in their previous quit attempts. The main products used were Nicotinell TTS, used by 195 purchasers, or Nicorette gum, ${ }^{28}$ used by 148 purchasers. Some respondents reported the use of more than one product previously. At the time of the study Nicotinell TTS had been available for purchase through pharmacy in New Zealand for about 18 months, while Nicorette gum had been available for nearly 10 years. The products Nicabate $^{29}$ [a transdermal nicotine productMarion Merrell Dow (known as Nicoderm in the United States)] and Nicobrevin (a non-nicotine product) were just starting to be heavily advertised during the period of the study.

PREVIOUS QUIT ATTEMPTS USING TRANSDERMAL NICOTINE

As detailed above, the number of previous attempts to quit smoking using a treatment course of Nicotinell TTS was reported by 195 out of $805(24.2 \%)$ total respondents. One previous attempt using Nicotinell TTS had been made by 170 of this group, two attempts by 23 , three attempts by two, and six attempts by one individual. For the first attempt the mean duration of use for each patch strength was similar and varied from 2.4 to 2.8 weeks. The maximum duration of use of any one patch strength was eight weeks. The mean total duration of patch use involving all strengths for the first attempt was 4.4 weeks, with a minimum of one week, a maximum of 13 weeks, and a median of three weeks.

For second attempts, the mean duration of use for each patch strength varied from 2.5 to 3.1 weeks. The mean total duration of patch use for all strengths for the second attempt was 4.3 weeks, with a minimum of one week, a maximum of 10 weeks, and a median of 3.5 weeks. 
Table 3 Interval between previous and present quit attempts for the 195 respondents restarting Nicotinell TTS

\begin{tabular}{ll}
\hline $\begin{array}{l}\text { Period since previous } \\
\text { attempt (months) }\end{array}$ & $\begin{array}{l}\text { Respondents } \\
(n=195) n(\%)\end{array}$ \\
\hline $0-3$ & $16(8.2)$ \\
$4-6$ & $28(14.4)$ \\
$7-9$ & $26(13.3)$ \\
$10-12$ & $48(24.6)$ \\
$>12$ & $77(39.5)$ \\
\hline
\end{tabular}

TEMPORAL RELATIONSHIP OF PREVIOUS PATCH

USE TO CURRENT QUIT ATTEMPTS

The temporal relationship of previous quit attempts using Nicotinell TTS to the present attempt was noted by 195 out of 805 (24.2\%) total respondents. The interval between the present attempt and the most recent past attempt is shown in table 3. For $151(77.4 \%)$ of these respondents this interval was greater than six months. Only $16(8.2 \%)$ of purchasers who had made a previous quit attempt using Nicotinell TTS had done so within the last three months. When duration of use was recorded, even if the current and previous courses of Nicotinell TTS were combined for these participants (which may well be inappropriate with a gap between courses), the longest combined usage would be 11 weeks. The mean duration of use overall for the previous course was 4.3 weeks, with a maximum duration of 10 weeks.

PATCH USAGE PATTERNS DURING CURRENT QUIT ATTEMPT

For 480 of $805(59.6 \%)$ total respondents, this was their first purchase of Nicotinell TTS for the current treatment course. Prior purchases during the current course of Nicotinell TTSthat is, during the present quit attempt-were reported by 316 out of $805(39.3 \%)$ total respondents.

Table 4 shows the usage pattern of the different patch strengths and the duration of use for 293 purchasers who had made prior purchases of Nicotinell TTS during the current treatment course and who recalled this information. The mean total duration of use of patches during the present attempt to quit smoking was 21.2 days, with a minimum of one day, a maximum of 91 days, and a median of 14 days. Only $10 \%$ of these respondents had used Nicotinell TTS for six weeks or more in the present attempt at the time of completion of the questionnaire.

CONCOMITANT SMOKING

Information about concurrent smoking was sought from the respondents who were purchasing Nicotinell TTS to continue their current treatment course. Of the 314 who gave

Table 4 Patch usage patterns during current quit attempt with Nicotinell TTS for 293 respondents

\begin{tabular}{llll}
\hline Patch & $\begin{array}{l}\text { Number of } \\
\text { respondents* } \\
(n=293)\end{array}$ & $\begin{array}{l}\text { Mean (SD) } \\
\text { duration } \\
\text { of use (days) }\end{array}$ & $\begin{array}{l}\text { Maximum } \\
\text { duration } \\
\text { of use (days) }\end{array}$ \\
\hline Nicotinell 30 & 183 & $16.8(9.6)$ & 56 \\
Nicotinell 20 & 156 & $15.9(12.3)$ & 90 \\
Nicotinell 10 & 39 & $16.8(10.9)$ & 42
\end{tabular}

$\star$ Some respondents reported the use of more than one patch strength.
Table 5 Side effects self-reported by 301 respondents purchasing Nicotinell TTS again during the current quit attempt

\begin{tabular}{lc}
\hline Side effect & $\begin{array}{c}\text { Respondents reporting } \\
(n=301) n(\%)\end{array}$ \\
\hline No side effects & $230(76.4)$ \\
Skin irritation & $35(11.6)$ \\
Sleep disturbance & $25(8.3)$ \\
Headache & $4(1.3)$ \\
Mouth/throat discomfort & $4(1.3)$ \\
Increased heart rate & $2(0.7)$ \\
Mood change & $2(0.7)$ \\
Sweating & $2(0.7)$ \\
Indigestion & $2(0.7)$ \\
Angina & $2(0.7)$ \\
Dizziness & $2(0.7)$ \\
Miscellaneous $\dagger$ & $8(2.7)$ \\
\hline
\end{tabular}

*Some respondents reported more than one side-effect. †Miscellaneous: one report each of sore eyes, breathing problems, sinus pain, stress, fatigue, kidney pain, liver discomfort, lung cancer.

information about concurrent smoking while using Nicotinell TTS during the present quit attempt, $225(71.6 \%)$ reported that they had stopped smoking altogether, and $89(28.3 \%)$ were still smoking. Of those who were still smoking, 85 reported on the number of cigarettes still smoked, which varied from one to 40 per day, with a median of five (compared with a median of 20 cigarettes per day before the current quit attempt). Analysis of the relationship between continued smoking while using Nicotinell, gender, and each of the number of years smoking, the number of cigarettes each day, and the age of the purchasers yielded no significant differences between the relevant subgroups.

\section{SIDE EFFECTS}

Information about side effects was sought from the respondents who were purchasing Nicotinell TTS to continue their current treatment course. Of the 301 who reported on side effects caused by Nicotinell TTS during their present quit attempt, $230(76.4 \%)$ reported no problems. There were reports of side effects by $71(23.6 \%)$ of the respondents. Of the total reports on side effects, skin irritation and sleep disturbances were the most common (table 5).

There were 23 purchasers who reported side effects and continued to smoke. There was no statistically significant relationship between concurrent smoking and the likelihood of experiencing side effects while using Nicotinell TTS.

\section{Discussion}

New Zealand was one of the first countries to allow non-prescription sale of transdermal nicotine; the product is classified as a pharmacy-only medicine, which restricts OTC sale to pharmacies. Pharmacists are expected to ask appropriate questions on sale of the product, and to provide counselling on its use. ${ }^{1314}$ The pharmaceutical companies that market the products in New Zealand (Nicotinell TTS - Ciba-Geigy Pharmaceuticals; Nicabate-Marion Merrell Dow Pharmaceuticals) also provide support to pharmacists and consumers in the form of written material (starter packs) and telephone helplines. The products are priced OTC to correspond 
approximately with the cost of continuing to smoke at the consumer's normal daily rate.

At the time of the start of the study, Nicotinell TTS had been available in New Zealand as a pharmacy-only medicine for approximately 18 months and Nicabate was just starting to be heavily marketed. Marketing was by direct advertising to the public in print and broadcast media, and to pharmacists by detailing and advertising in professional journals. At the time of the launch of Nicotinell TTS, the company (Ciba-Geigy New Zealand) provided extensive educational programmes to pharmacists on the use of the product.

Our study was initiated by open invitation to all community pharmacies in New Zealand. The total number of pharmacies generating participants was 149 from a total of 1108 contacted-a participation rate of $13.5 \%$. It is difficult to say whether this was a "good" participation rate as this approach has not been attempted before. We were actually quite pleased with this response as there was no incentive for the pharmacies to become involved other than a willingness to assist in research. Given the busy and complex nature of community pharmacy practice, it was encouraging that a large number of pharmacists took the time and trouble to participate.

There was no attempt to differentiate between participating and non-participating pharmacies. It was not the intention of the study to assess the efficacy of the treatment or counselling provided by the pharmacists. The focus was on how transdermal nicotine was being used by purchasers in a non-prescription setting, and the pharmacists' role was essentially to recruit agents for this research. For this reason the design was deliberately non-interventional.

It is possible that purchasers who agreed to participate were different in some way from those who did not. There was no attempt to assess this and the methodology would have been strengthened by a validation substudy. Anecdotally, pharmacists reported very few refusals when purchasers were invited to participate.

The study attempted to provide a "snapshot" of the ways in which consumers were using transdermal nicotine when purchased OTC. There was no attempt to establish efficacy and the study was not a clinical trial. It might rather be viewed as a form of postmarketing surveillance in a pharmacy setting whereby the "real life" use of the product was investigated. The methods employed were exploratory, there being relatively few reports of similar studies in the literature. ${ }^{15} 20$ The study has demonstrated that useful data can be obtained in this fashion. In some countries a proportion of the population may prefer direct purchase of some medicines in an OTC setting, avoiding the expense and inconvenience of a physician's visit and reflecting an increasing move towards selftreatment.

OTC availability of transdermal nicotine products may lead to fewer opportunities for medical surveillance of their use, or for appropriate counselling and support to be offered to users. It could be argued that the effectiveness of transdermal nicotine as a quit-smoking aid is enhanced by intensive medical counselling, and there is evidence to support this view. ${ }^{30-34}$ On the other hand, a number of studies have demonstrated that less intensive or minimal intervention is still associated with successful use of the product when compared with placebo patches. ${ }^{15}{ }^{35-40}$ In the context of this study we have assumed minimal intervention (routine initial questioning and counselling on first purchase) on the part of pharmacists selling transdermal nicotine, although we did not attempt to control or measure this aspect of the transaction.

In the overall context of smoking cessation strategies, a "stepped-care" approach for transdermal nicotine has been advocated..$^{15142}$ It could be argued that OTC availability allows an additional opportunity for some smokers who would initially prefer self-treatment as part of their quit-smoking attempt. The opportunity then exists for identification and referral of treatment failures to the next step of the strategy.

Apart from considerations of efficacy, precautions for nicotine usage still apply when the consumer has underlying cardiovascular morbidity or continues to smoke, or both. There are case reports of the onset of angina, myocardial infarction, and cerebral ischaemia in transdermal nicotine users, but the reported incidence of these is less than expected in a population of smokers, suggesting coincidence rather than a causal relationship. ${ }^{43-46}$ Continuing to smoke is inconsistent with the use of transdermal nicotine as an aid to quit, but little is known of the way in which products are used in practice (with or without prescription), and whether "at risk" patients are being identified and followed.

Another concern regarding the availability of transdermal nicotine is the potential for "transfer of addiction" from cigarettes to nicotine products. There are a number of reports of this occurring with nicotine gum, and some commentators predict that a similar potential exists with nicotine spray or inhaler products. ${ }^{26} 27$ The release characteristics and pharmacokinetic profile of transdermal nicotine would appear to minimise the risk of addiction, and there is no evidence that this has developed in the trials performed to date. ${ }^{72347}$ One of the aims of this study was to assess the potential for the development of "transfer of addiction" in the OTC use of transdermal nicotine.

Approximately $60 \%$ of purchases for the current course of Nicotinell TTS were by new users of the product. For those reporting previous attempts to quit smoking using the product, more than $90 \%$ had used it more than three months before the current quit attempt and fewer than $10 \%$ of such purchasers had made a quit attempt using Nicotinell TTS within the previous three months. Even if the current and previous courses of the product are combined for these participants, the longest combined usage would be 11 weeks. The maximum duration of use for the previous course was recorded as 10 weeks. Accordingly, we could 
find no evidence of usage of Nicotinell TTS for longer than the manufacturer's recommended maximum of 12 weeks. These data suggest that there is no "transfer of addiction" from cigarettes to transdermal nicotine. It has to be acknowledged that these are not conclusive data and the only real way to address this issue would be through a prospective study.

It was of interest to note that the actual duration of patch use in the "real life" context in this study was about four or five weeks on average, considerably shorter than the manufacturers' recommendations of up to 12 weeks of treatment with reducing patch strength. Pharmacists reported that the usual purchase was for one week's supply at a time, with relatively few purchases for more than three weeks' supply at a time. Perhaps this pattern of purchase could be exploited more effectively by pharmacists in terms of support to purchasers with their quit-smoking attempts. This purchase pattern suggests that encouraging compliance and sufficient use of the product is a greater problem than the potential for "transfer of addiction".

Some $28 \%$ of respondents reported continuedsmokingwhileusingtransdermalnicotine, although the average number of cigarettes smoked per day was substantially less than that in their previous smoking history. The manufacturer's instructions clearly state that purchasers should stop smoking altogether while using the patches. ${ }^{14}$ These instructions are meant to be reinforced by pharmacists when selling the product. No statistically significant relationship was found in this study between reported side effects with the use of transdermal nicotine and concomitant smoking while using the product.

Ideally, the use of transdermal nicotine should result in complete smoking cessation ${ }^{4}$; however, in many cases this obviously does not occur. Several authors have argued that concomitant smoking does not necessarily signify failure of the product ${ }^{6}{ }^{48}$; others propose that early smoking while using transdermal nicotine is a strong predictor of failure to quit smoking. ${ }^{15} 49$ The reduction in intake of harmful cigarette smoke and the demonstration to the user that a substantial reduction in cigarette consumption can be achieved may be benefits in themselves. The cohort of transdermal nicotine users who continue to smoke may not be able to achieve abstinence without further counselling or intervention by health professionals. This reinforces the concept of a "stepped-care" approach to smoking cessation with the opportunity to identify those smokers who require more intensive therapy. ${ }^{41} 42$

Side effects were reported by $24 \%$ of Nicotinell TTS users in the current treatment course, with skin reaction and sleep disturbances the most frequently reported. These findings are consistent with previous studies. ${ }^{56}$ No serious adverse effects were described.

Although a number of purchasers reported previous medical conditions, mainly cardiovascular in nature, it did not appear that those who had pre-existing medical conditions experienced side effects more often than healthy respondents.
In summary, this study has provided useful preliminary data on the non-prescription availability of Nicotinell TTS. Within the limitations of the methods used, the actual duration of use of the product appeared to be shorter than that recommended by the manufacturer, and there was no evidence of transfer of addiction from cigarettes to transdermal nicotine. Concomitant smoking while using Nicotinell TTS was reported by a fairly high proportion $(28 \%)$ of users; this did not, however, lead to an increased rate of reporting of side effects.

Drs Shaw, Ferry, and Tucker have received funding for clinical research and consulting activities for this project from Ciba-Geigy New Zealand Limited, Private Bag 19-999, Avondale, Auckland, New Zealand.

1 Palmer KJ, Buckley MM, Faulds, D. Transdermal nicotine: a review of its pharmacodynamic and pharmacokinetic properties, and therapeutic efficacy as an aid to smoking cessation. Drugs 1992;44:498-529.

2 Benowitz NL. Nicotine replacement therapy: what has been accomplished-can we do better? Drugs 1993;45:157-70.

3 Fiore MC, Jorenby DE, Baker TB, et al. Tobacco dependence and the nicotine patch: clinical guidelines for effecdence and the nicotine patch: clinical
tive use. $\mathscr{F} A M A$ 1992;268:2687-94.

4 Fiore MC, Bailey WC, Cohen SJ, et al. Smoking cessation. Clinical Practice Guideline No 18. Rockville, Maryland: US Department of Health and Human Services, Public Health Service, Agency for Health Care Policy and Research, April 1996. (AHCPR Publication No 96-0692.)

5 Silagy C, Mant D, Fowler G, et al. Meta-analysis on efficacy of nicotine replacement therapies in smoking cessation. Lancet 1994;343:139-42.

6 Fiore MC, Stevens SS, Jorenby DE, et al. The effectiveness of the nicotine patch in smoking cessation: a meta-analysis. of the nicotine patch in sm.

7 Cepada-Benito A. A meta-analytical review of the efficacy of nicotine chewing gum. $\mathcal{F}$ Consult Clin Psychol 1993;61:82230 .

8 Tonnesen P, Norregaard J, Mikkelsen K, et al. A double blind trial of a nicotine inhaler for smoking cessation. FAMA 1993;269:1268-71

9 Sutherland G, Stapleton JA, Russell MA, et al. Randomised controlled trial of nasal nicotine spray in smoking cessation. Lancet 1992;340:324-9.

10 Hjalmarson A, Franzon M, Westin A, et al. Effect of nicotine nasal spay on smoking cessation. A randomized, placebocontrolled, double-blind study. Arch Int Med 1994; 154:2567-72.

11 Drug Abuse Advisory Committee, Food and Drug Administration. Nicotine substitution products. Rockville, Maryland: US Food and Drug Administration, 1992.

12 McNagny SE, Ahluwalia JS. Use of over-the-counter nicotine patch for smoking cessation: prudent or premature? (Letter.) $\mathcal{F} A M A$ 1996;276:371.

13 Anon. New nicotine patch helps smokers quit. NZ Pharm 1990;10:28.

14 Anon. Nicotinell TTS product insert. Auckland, New Zealand: Ciba-Geigy (NZ), 1991.

15 Orleans CT, Resch N, Noll E, et al. Use of transdermal nicotine in a state-level prescription plan for the elderly: a first look at 'real-world' patch users. fAMA 1994;271:6017.

16 Fincham JE. Smoking cessation: treatment opportunities and the pharmacist's role. Am Pharm 1992;NS32:62-70.

17 Smith MD, McGhan WF, Lauger G. Pharmacist counseling and outcomes of smoking cessation. Am Pharm 1995; NS35:20-9.

18 Berbatis CG. The pharmacist's involvement in smoking cessation and the use of Nicorette. Pharm F 1991;247:212 14

19 Nathan A. Stopping smoking: pharmacists' contribution. Pharm F 1991;246:293-4.

20 Sinclair HK, Bond CM, Lennox AS, et al. Nicotine replacement therapies: smoking cessation outcomes in a pharmacy setting in Scotland. Tobacco Control 1995;4:338-43.

21 Benowitz NL. Pharmacologic aspects of cigarette smoking and nicotine addiction. N Engl f Med 1988;319:1318-30.

22 Benowitz NL. Pharmacodynamics of nicotine: implications for rational treatment of nicotine addiction. $\mathrm{Br} \mathcal{F}$ Addict 1991;86:495-9

23 Pickworth WB, Bunker EB, Henningfield, JE. Transdermal nicotine: reduction of smoking with minimal abuse liability. Psychopharmacology 1994;115:9-14.

24 Gorsline J, Gupta SK, Dye D, et al. Steady state pharmacokinetics and dose relationship of nicotine delivered from Nicoderm (nicotine transdermal system). $\mathcal{F}$ Clin Pharmacol 1993;33:161-8.

25 Gupta SK, Okerholm RA, Coen P, et al. Single- and multiple-dose pharmacokinetics of Nicoderm (nicotine transdermal system). F Clin Pharmacol 1993:33:169-74.

26 Hughes JR. Dependence potential and abuse liability of nicotine replacement therapies. Biomed Pharmacother 1989;43:11-17. 
27 Hurt RD, Offord KP, Lauger GG, et al. Cessation of long-term nicotine gum use-a prospective, randomized trial. Addiction 1995;90:407-13.

28 Anon. Nicorette product insert. Auckland: New Zealand: Pharmacia (NZ), 1990

29 Anon. Nicabate product insert. Auckland, New Zealand Marion Merrell Dow (NZ), 1992.

30 Kottke TE, Battista RN, DeFriese GH, et al. Attributes of successful smoking cessations in mA 1988:259.2882 9 -

31 Baillie A, Mattick RP, Hall W, et al. Meta-analytic review of the efficacy of smoking cessation interventions. Drug Alcothe efficacy of smoking ces

32 Fiscella K, Franks P. Cost-effectiveness of the transdermal nicotine patch as an adjunct to physicians' smoking cessation counseling. $\mathcal{F A M A}$. 1996;275:1247-1251.

33 Hurt RD, Dale LC, Frederickson PA, et al. Nicotine patch therapy for smoking cessation combined with physician advice and nurse follow-up: one-year outcome and percentage of nicotine replacement. $7 A M A$ 1994;271:595600.

34 Imperial Cancer Research Fund General Practice Group. Effectiveness of a nicotine patch in helping people stop smoking: results of a randomised trial in general practice. smoking: results of a rand

35 Martin PD, Robinson GM. The safety, tolerability and efficacy of transdermal nicotine (Nicotinell TTS) in initially hospitalised patients. NZ Med F 1995;108:6-8.

36 Cummings KM, Biernbaum, RM, Zevon MA, et al. Use and effectiveness of transdermal nicotine in primary care settings. Arch Fam Med 1994;3:682-9.

37 Daughton DM, Heatley SA, Prendergast JJ, et al. Effect of transdermal nicotine delivery as an adjunct to lowintervention smoking cessation therapy. Arch Intern Med 1991;151:749-52.
38 Lennox AS, Taylor RJ. Factors associated with outcome in unaided smoking cessation, and a comparison of those unaided smoking cessation, and a comparison of those Who have never tried to

39 Orleans CT, Schoenbach VJ, Wagner EH, et al. Self-help quit smoking interventions: effects of self-help materials, social support instructions, and telephone counseling. $\mathcal{F}$ Consult Clin Psychol 1991;59:439-48.

40 Jorenby DE, Smith SS, Fiore ME, et al. Varying nicotine patch dose and type of smoking cessation counseling. fAMA 1995;274:1347-52.

41 Orleans CT. Treating nicotine dependence in medical settings: a stepped-care model. In: Orleans CT, Slade J, eds. Nicotine addiction: principles and management. New York, NY: Oxford University Press, 1993:145-61.

42 Abrams DB, Orleans CT, Niaura RN, et al. Treatment issues in smoking cessation: a stepped-care approach. Tobacco Control 1993;2(suppl): 17-34.

43 Pierce JR. Stroke following application of a nicotine patch (letter). Ann Pharmacother 1994;28:402.

44 Fiore MC, Hartman MJ. Side effects of nicotine patches (letter). f $A M A$ 1993;270:2735.

45 Warner JG, Little WC. Myocardial infarction in a patient who smoked while wearing a nicotine patch (letter). Ann Intern Med 1994;120:695.

46 Jackson $M$. Cerebral artery narrowing with nicotine patch (letter). Lancet 1993;342:236-7.

47 Mulligan SC, Masterton JG, Devane JG, et al. Clinical and pharmacokinetic properties of a transdermal nicotine patch. Clin Pharmacol Ther 1990;47:331-7.

48 Haxby D, Sinclair A, Eiff MP, et al. Characteristics and perceptions of nicotine patch users. 7 Fam Pract 1994;38:45964

49 Kenford SL, Fiore MC, Jorenby DE, et al. Predicting smoking cessation: who will quit with and without the nicotine patch. $\mathcal{F A M A} 1994 ; 271: 589-94$.

\section{Tobacco Control <http://www.tobaccocontrol.com>}

Visitors to the world wide web can now access Tobacco Control either through the BMJ Publishing Group's home page <http://www.bmjpg.com> or directly by using its individual URL $<$ http://www.tobaccocontrol.com $>$. There they will find the following.

- Current contents list for the journal

- Contents lists of previous issues

- Members of the editorial board

- Subscribers' information

- Instructions for authors

- Details of reprint services.

There is also a longer version of the "Play It Again" section of Tobacco Control that was published in the Winter 1996 issue of the journal, cataloguing tobacco-related quotes made during the 1996 United States presidential campaign.

A hotlink gives access to:

- BMJ Publishing Group home page

- British Medical Association web site

- Online books catalogue

- BMJ Publishing Group books

The web site is at a preliminary stage and there are plans to develop it into a more sophisticated site. Suggestions from visitors about features they would like to see are welcomed. They can be left via the opening page of the BMJ Publishing Group site or, alternatively, via the journal page, through "About this site". 